\title{
Perspectives
}

\section{Perspectives of a Farmer Digital Expert Assistant System}

\author{
Vigneswaran Narayanamurthy \\ Faculty of Electrical and Electronics Engineering, \\ Universiti Malaysia Pahang \\ Pekan 26600, Malaysia. \\ pel13006@stdmail.ump.edu.my
}

\author{
Fahmi Samsuri \\ Faculty of Electrical and Electronics Engineering, \\ Universiti Malaysia Pahang \\ Pekan 26600, Malaysia. \\ fahmi@ump.edu.my
}

\begin{abstract}
Global positioning system (GPS) based farmer digital expert assistant systems (FDEAS) are capable of analyzing the agricultural field and environmental factors associated with the field. The agricultural yield to be harvested, depends on the liquidity content of the soil, the mineral content of the soil, the geographical position of the field, the microbial content of the soil and the temperature of the environment. Other parameters include irrigation, spraying of chemicals, animals or intruders getting into the field, etc. Such a system monitors all these parameters and provides the appropriate values and suggestions to the farmers. Several factors are monitored using different set of sensors. The location, specified by the GPS, can be compared to existing databases of soil maps and thus provide the nature and type of crop to be cultivated with all specifications to obtain maximum yield at that location. Cameras may be employed to continuously monitor the field and initiate alerts. All sensor outputs and systems can be integrated with a GSM modem which sends alert messages as SMS or recorded audio alerts when required. Such a system would ensure real time monitoring and should provide expert assistance for attaining maximum efficiency. It would act as a holistic system for analyzing, monitoring, alerting and assisting farmers at different stages of farming.
\end{abstract}

Keywords-Global positioning system; agriculture; sensors; Agricultural system; GSM; Farming expert system

\section{INTRODUCTION}

Agriculture needs to be assisted by technology in order to enhance its efficiency. In fact, a country is tagged as developed only when the field of agriculture grows in parallel or in pace with the other fields such as infrastructure, technology, equipments, etc. The implementation of advanced and efficient techniques by engineers to improve the yield quality and quantity has become a necessary criterion [1]. Several works have been published regarding technology implementation in agriculture aiming to improve productivity and sustainability. Several expert systems have been developed for agriculture applications, but still none is able to provide a holistic solution [2-16].
Laser level technology has been tested on farm-level information from Moga district of Punjab and it has shown that it can help save irrigation water and energy by 24 per cent and obtain 4.25 per cent higher yields [17]. Theories about biotechnology institutions and their evolution in sectoral innovation systems with concept and model application from complex system theory have been studied in [18]. Studies also have measured inequality and lagging states by applying the convergence principle by taking both per capita income and per capita agricultural income as the sources of convergence. Indian agricultural sector is not performing in pace with the national economy and need for strategies to improve the performance of this sector has been felt [19]. Emerging trends and innovations in agricultural field demand the private sector to be involved to enhance productivity but also the public sector for guidance [20].

Varieties of sensors and techniques can be applied to perform diverse measures in wide research areas. Use of spectral reflectance techniques for aiding decisions relating to crop establishment, weed control, crop protection and crop nutrition has been studied. Uses, limitations, areas requiring further work and future potential as a commercial tool for precision agriculture have also been mentioned. Spectral reflectance techniques have been concluded to not be that suitable for measuring soil properties as other technologies are found to be better suited for this application. It is also stated that spectral reflectance techniques are capable of detecting weeds against a soil background and are capable of providing useful information about crop canopy that can be used as a component in determining the fungicide, growth regulator and nitrogen inputs to a cereal crop [21].

Different sensing methodologies to provide accurate information on crop, soil, climate, and environmental conditions are strongly recommended for modern agricultural management. It should be noted that is has been stated that almost every sensing technique may find an application in agriculture and food industry [22]. Stresses identification and removal by suitable mechanical working have been studied. 
Body part discomfort score and overall discomfort rating experienced by the subjects have been estimated. Oxygen consumption rate and heart rate have been used for physiological cost estimation [23]. Central composite rotatable design based experiments have been conducted to determine the optimum processing conditions of expansion ratios of extruded snacks made from millet and legume using response surface methodology. The evaluated variables included die head temperatures, barrel temperatures, screw speed, blend ratio and moisture content [24]. Digitized city maps along with a GPS sensor on a mobile computer can be used to provide location and directions to drivers [25]. GPS can also be used to identify the grazing areas [26]. Techniques have also been developed for land use planning [6].

A Knowledge Based System may be designed to simulate problem-solving behavior of an expert in a narrow domain or discipline in which expert systems unite individual expertise in all disciplines, e.g., plant pathology, entomology, horticulture and agricultural meteorology. Since the evolution of Artificial Intelligence various expert systems have been employed on agriculture [9]. Mainly six types of farming systems analysis and intervention have been evolved over the last 40 years, namely: (1) economic decision analysis based on production functions, (2) dynamic simulation of production processes, (3) economic decision analysis linked to biophysical simulation, (4) decision support systems, (5) expert systems, and (6) simulation-aided discussions about management in an action research paradigm. A recent advance was made in increasing model comprehensiveness in simulating farm production systems via reference to Agricultural Production Systems Simulator (APSIM) [10].

Environmental concerns have led to the emergence of the integrated management of pest and pesticides (IMPP). Although the environmental and economic benefits of IMPP are beyond doubt, its use has been somewhat limited due to the required amount of knowledge on climate, topography, soil type of the farm, agronomic practices, crop phenology, biology and damage potential of the pests and options available for suppressing their population below the economic injury levels. Since this knowledge is within expert's level, in order to make it available to farmers, an expert system namely CPEST for managing pest and diseases of coffee in a developing country has been developed [11]. An evaluation research study was conducted for the effectiveness of expert systems in India. It concluded that there was an enhancement in decision making of the extension personnel after using the expert system on maize [12]. Expert systems were found to be feasible to use as a decision support tool for transfer of agricultural technologies to the farming community [12].

A decade review on expert system methodologies concluded that expert systems methodologies mainly evolve using the following eleven categories: rule-based systems, knowledge-based systems, neural networks, fuzzy ESs, objectoriented methodology, case-based reasoning, system architecture, intelligent agent systems, database methodology, modeling, and ontology together with their applications for different research and problem domains [3]. Suggestions were made that different social science methodologies, such as psychology, cognitive science, and human behavior could implement expert systems as another kind of methodology. The ability to continually change and obtain new understanding is the driving power of such systems [3]. Expert systems were also used in land-use planning in general and site selection in particular. Assessment of the usefulness of each system for the urban planner has been investigated in [6].

As an initiation step to the implementation of advanced technology in agriculture, a farmer digital expert assistant system (FDEAS) is described in this paper. The goal of the system is to help farmers in cultivation using advanced engineering techniques at low cost and thereby reduce the gap between farmers and latest technological advancement. Most of the existing studies were on the implementation of technologies to improve individual processes like the efficiency of seeds, pesticides and insecticides application, etc. In this case the approach it to incorporate electronic, instrumentation and information technology to develop an integrated digital assistant to address a system of processes. The system developed is designed to bridge the adoption gap between the farmer and technology by bypassing the complexities involved in handling the device and exposing only the simple procedures.

\section{PROCESS DESIGN AND INSTRUMENTATION}

The FDEAS carries out a sequenced range of actions starting before the process of sowing the seed and reaching the final stage of harvesting. It would constantly monitor the field and provide alerts, suggestions, solutions and inferences to the farmer in audio, visual and SMS (Short Message Service) form. The FDEAS comprises of several input modules and sensors to consider all the environmental factors that contribute to the quality and quantity of the yield. Its basic architecture is depicted in Figure 1. An FDEAS would basically comprise of Global Positioning System (GPS) receivers, temperature sensors, liquidity sensors, chemical sensors, gas sensors, cameras, LCD displays, speakers, GSM infrastructure and battery power boxes. The heart of the FDEAS module would be a microcontroller based system which would acquire, analyze and evaluate various sensor information and store data for future use. The system components would be customized by the farmer as per the budget and the nature of the field.

GPS provides reliable positioning, navigation, and timing services to civilian users on a continuous worldwide basis freely available to all [27]. The GPS system in this module would acquire the location of the field. The location identified would be compared to the database of Soil and Watershed Atlas developed by Agricultural Engineering Department of the Indian Government [28]. Results should provide soil chemical properties, erosion factors, available water supply, soil qualities, list of crops that can be grown and the estimated amount of yield that can be obtained at that particular season and location. This data is not known to many of the practicing farmers in villages and they infer these details by using a trial and error method by cultivating different varieties of crops and checking their yields. Thus, consuming a huge amount of time, labor and money to reach a simple decision. Once the crop is chosen, the FDEAS would provide complete specifications of 
temperature, liquid content of soil, microbial activity and amount of fertilizers, insecticides and pesticides to be added for the perfect growth of crops. In addition, the latitude and longitudinal information of FDEAS module would be linked to the weather station database [30,31] to evaluate the current temperature and forecast it for the specified region. The developed system would simplify this task and provides results instantaneously.

\section{A. Sensor Components}

The following sensors should be implemented: temperature sensor, liquidity sensor, absorption technique based chemical sensors, gas sensor and a camera. The atmospheric ambient air temperature can be implemented using a commercially available sensor (e.g. linear Temperature sensor LM35). The output from the temperature sensor would be interfaced with the microcontroller for further conversion of sensor voltage to temperature readings. The sensor would constantly monitor atmospheric temperature and alert the farmer stating whether the temperature is favorable or not so that he could perform certain remedy measures. Regarding the liquidity sensor and supply voltage an example would be: $3.3 \mathrm{~V}$ or $5 \mathrm{~V}$, Operating current: less than $20 \mathrm{~mA}$, Output voltage :0-2.3 V [2.3V is completely immersed in water voltage value], $5 \mathrm{~V}$ power supply. An analog output sensor should be chosen. These sensors will be placed under the ground to determine the liquid/moisture content present in the soil through electrical conductivity (which is directly related to the moisture content). The analog output voltage readout would be further processed by the microcontroller. If the soil water content threshold is not reached, the microcontroller would release a mechanical valve to irrigate the field. The valve would be shut automatically once sufficient water content is attained.

Chemical sensors would be used to monitor the concentration of fertilizer, pesticide and insecticide applied. These chemical sensors can be customized based on field requirements. Nutrients usually present in soil are ammonium nitrate, available phosphorus, potassium, organic matter, total nitrogen, nitrogen and other nine trace elements like calcium, magnesium, sulfur, iron, manganese, boron, zinc, copper, chlorine and silicon. Fertilizer nutrients are elemental fertilizer nitrogen, phosphorus and potassium; complex (mixed) in Hefei and urea ammonium nitrogen, nitrate nitrogen, phosphorus, potassium, biuret; organic fertilizer available nitrogen, available phosphorus, $K$, total nitrogen, total phosphorus, total potassium, organic matter, various humic acid, and other trace elements like calcium, magnesium, sulfur, iron, manganese, boron, zinc, copper, chlorine, silicon. The system should be designed in such a way that when safety threshold limit exceeds, the farmer would be alerted to stop chemical spraying. The thresholds can be varied based on the nature of the crops.

Microbes play a major role in healthy growth of crops and to perform efficient cultivation the amount of microbes present should be monitored constantly. To achieve this task $\mathrm{N}_{2} \mathrm{O}$ and other types (depending on the microbes) of gas sensors can be employed which would monitor the concentration of gas liberated by the microbes, which is directly proportional to the amount of microbes. Thus, it will be able to detect $\mathrm{CH}_{4}, \mathrm{H}_{2} \mathrm{~S}$,
$\mathrm{CO}_{2}$. The nitrous oxide sensor employed may be a typical infrared sensor which measures concentrations ranging from 0 $1000 \mathrm{ppm}$. Working current for these sensors is less than $1 \mathrm{~mA}$.

Cameras should be employed to provide security to the system and to the crop from theft and intruders. Simple image subtraction techniques may be employed to detect movement. These methods can also be extended to detect animal grazing and presence of life threatening animals. As another alternative, a set of motion sensors widely distributed throughout the field may be used. The latter would be a better option to employ if vast fields are to be monitored, as the field of vision would be a limitation to the camera.

\section{B. Output Modes}

Output modules would consist of three modes of communication to farmers which are LCD, Speaker and SMS using GSM. All sensor alerts mentioned above will be displayed in the LCD present in the FDEAS module. In order to keep the farmer continuously updated even during his absence, two more output modules (speaker and SMS) should be implemented.

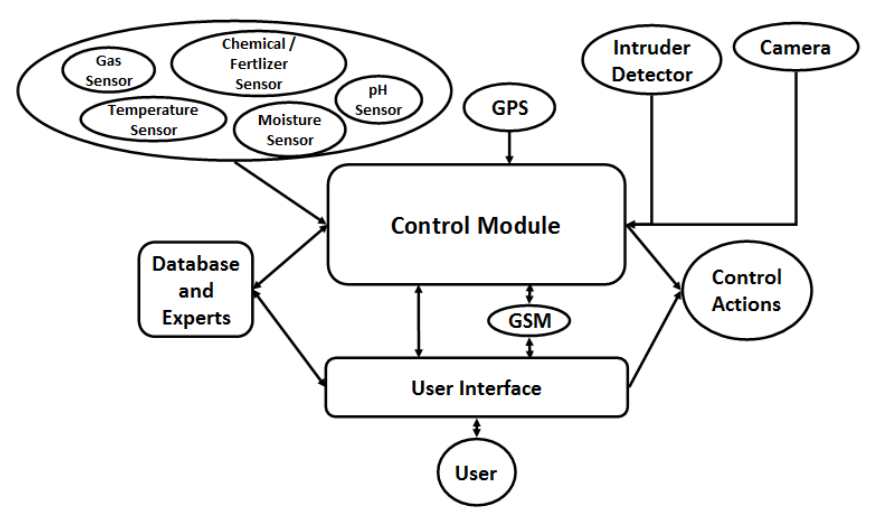

Fig. 1. FDEAS architecture.

\section{DISCUSSION AND FUTURE PROSPECTIVE}

FDEAS should be evaluated in field trials to decide its efficiency and stand-alone capability. Sensors calibration is to be checked and corrected in regular intervals. Initial cost should be expected to be high, as it involves monitoring of several parameters, but in the end affordable for the service rendered by the system. Since the system is of standalone type, the optional accessories of sensors can be omitted depending upon the budget. Government support in manufacturing would help in further reducing the cost. In future IVRS can also be used for further improvement. Solar energy can be used to charge the batteries. Security against theft and robustness against tough climatic conditions should also be considered.

\section{REFERENCES}

[1] J. V. Stafford, "Implementing precision agriculture in the 21st century", Journal of Agricultural Engineering Research, Vol. 76, pp. 267-275, 2000 
[2] A. Rafea, "Expert System Applications: Agriculture," Central Laboratory for Agricultural Expert Systems, PO Box, vol. 100, 1998.

[3] S.-H. Liao, "Expert system methodologies and applications-a decade review from 1995 to 2004”, Expert Systems with Applications, Vol. 28, pp. 93-103, 2005

[4] J. McKinion, H. Lemmon, "Expert systems for agriculture”, Computers and Electronics in Agriculture, Vol. 1, pp. 31-40, 1985

[5] R. E. Plant, "Expert systems in agriculture and resource management", Technological Forecasting and Social Change, Vol. 43, pp. 241-257, 1993

[6] F. Witlox, "Expert systems in land-use planning: An overview", Expert Systems with Applications, Vol. 29, pp. 437-445, 2005

[7] R. Doluschitz, W. Schmisseur, "Expert systems: applications to agriculture and farm management”, Computers and Electronics in Agriculture, Vol. 2, pp. 173-182, 1988

[8] P. Jones, "Agricultural applications of expert systems concepts", Agricultural Systems, Vol. 31, pp. 3-18, 1989

[9] G. Prasad, A. V. Babu, "A Study on Expert Systems in Agriculture”, Extension of Technologies: From Labs to Farms, p. 297, 2008

[10] B. A. Keating and R. McCown, "Advances in farming systems analysis and intervention," Agricultural systems, vol. 70, pp. 555-579, 2001.

[11] G. Mansingh, H. Reichgelt, K. M. O. Bryson, "CPEST: An expert system for the management of pests and diseases in the Jamaican coffee industry”, Expert Systems with Applications, Vol. 32, pp. 184-192, 2007

[12] S. Sivakami, C. Karthikeyan, "Evaluating the effectiveness of expert system for performing agricultural extension services in India”, Expert Systems with Applications, Vol. 36, pp. 9634-9636, 2009

[13] T. Trivedi, D. Ahuja, "Integrated pest management: approaches and implementation”, The Indian Journal of Agricultural Sciences, Vol. 81, 2011

[14] H. Ravisankar, U. Sreedhar, K. Sivaraju, "Expert system for insect pests of agricultural crops”, The Indian Journal of Agricultural Sciences, Vol. 84, 2014

[15] V. Kumar, A. Kumar, C. Chattopadhyay, "Design and implementation of web-based aphid (Lipaphis erysimi) forecast system for oilseed Brassicas”, The Indian Journal of Agricultural Sciences, Vol. 82, 2012

[16] B. Gangwar, K. Prasad, “Cropping system management for mitigation of second-generation problems in agriculture”, Indian Journal of Agricultural Science, Vol. 75, pp. 65-78, 2005

[17] B. Kaur, S. Singh, B. Garg, J. Singh, J. Singh, "Enhancing water productivity through on-farm resource conservation technology in
Punjab agriculture”, Agricultural Economics Research Review, Vol. 25, pp. 79-85, 2012

[18] J. Niosi, "Complexity and path dependence in biotechnology innovation systems”, Industrial and Corporate Change, Vol. 20, pp. 1795-1826, 2011

[19] T. K. Das, L. Mishra, "Including Agriculture in Sustaining Economic Growth of India”, IUP Journal of Applied Economics, Vol. 9, p. 69, 2010

[20] A. Gulati, "Emerging Trends in Indian Agriculture: What can we learn from these", Agricultural Economics Research Review, Vol. 22, pp. 171-184, 2009

[21] I. Scotford, P. Miller, “Applications of spectral reflectance techniques in northern European cereal production: a review”, Biosystems Engineering, Vol. 90, pp. 235-250, 2005

[22] S. Li, A. Simonian, B. A. Chin, "Sensors for agriculture and the food industry”, The Electrochemical Society Interface, Vol. 19, p. 41, 2010

[23] M. S. Khidiya, A. Bhardwaj, “An ergonomic approach to design hand tool for agricultural production”, Work (Reading, Mass.), Vol. 41, pp. 1335-1341, 2011

[24] S. K. Chakraborty, D. S. Singh, B. Kumbhar, S. Chakraborty, "Process optimization with respect to the expansion ratios of millet - and legume (pigeon pea) - based extruded snacks", Journal of Food Process Engineering, Vol. 34, pp. 777-791, 2011

[25] G. Dommety, R. Jain, "Potential networking applications of global positioning systems (GPS)”, arXiv preprint cs/9809079, 1998

[26] S. Rutter, N. Beresford, G. Roberts, "Use of GPS to identify the grazing areas of hill sheep”, Computers and Electronics in Agriculture, Vol. 17, pp. 177-188, 1997

[27] J. Agarwal, "Innovations \& Developments in Financing and Investment in Agriculture and Rural Development (with special reference to India and Hungary) ”, Finance India, 2007

[28] A. E. Department. (1998, 17-11-2015). District Soil \& Watershed Atlas Website. Available: http://www.aedatlas.tn.nic.in/

[29] USDANRCS. Web Soil Survey. Available: http://websoilsurvey.nrcs.usda.gov/app/HomePage.htm

[30] K. S. K. K. Apurva Sanghi, and James W. McKinsey, Jr., india agriculture and climate data set, available: http://ipl.econ.duke.edu/dthomas/dev_data/datafiles/india_agric_climate. htm

[31] K. K. Kumar, J. Parikh, "Indian agriculture and climate sensitivity", Global Environmental Change, Vol. 11, pp. 147-154, 2001 